\title{
Diallyl trisulfide induces osteosarcoma cell apoptosis through reactive oxygen species-mediated downregulation of the PI3K/Akt pathway
}

\author{
HONGLIANG WANG ${ }^{1}, \mathrm{NA} \mathrm{SUN}^{3}, \mathrm{XIN} \mathrm{LI}^{1}, \mathrm{KA} \mathrm{LI}^{1}$, JIGUANG TIAN $^{2}$ and JIANMIN LI ${ }^{1}$ \\ Departments of ${ }^{1}$ Orthopedics and ${ }^{2}$ Emergency, Qilu Hospital, Shandong University, Ji'nan, Shandong 250012; \\ ${ }^{3}$ Shandong Institute of Medicine and Health Information, Shandong Academy \\ of Medical Sciences, Ji'nan, Shandong 250062, P.R. China
}

Received February 4, 2016; Accepted March 15, 2016

DOI: $10.3892 /$ or.2016.4722

\begin{abstract}
Diallyl trisulfide (DATS) is a natural organosulfur compound isolated from garlic, and has been reported to possess anticancer activities. However, the cancer growth inhibitory effects and molecular mechanisms in human osteosarcoma cells have not been well studied. The present study demonstrated that DATS significantly reduced cell viability in a dose- and time-dependent manner in MG63 and MNNG/HOS cells. DATS-induced G0/G1 phase arrest was found to correlate with a decrease in cyclin D1 in concomitance with an increase in $\mathrm{p} 21$ and $\mathrm{p} 27$. DATS induced a marked increase in reactive oxygen species (ROS) levels and collapse of mitochondrial membrane potential $\left(\Delta \psi_{\mathrm{m}}\right)$ in the osteosarcoma cells. DATS induced apoptosis in the MG63 and MNNG/HOS cells via inhibition of the PI3K/Akt signaling pathway and through the mitochondrial apoptotic pathway. The efficiency of DATS basically approached the efficacy of LY294002, a specific PI3K inhibitor. However, $N$-acetylcysteine (NAC), a general ROS scavenger, completely blocked the DATS-induced ROS increase, inhibition of the PI3K/Akt pathway and cell apoptosis. Overall, DATS has the potential to be developed as a new anticancer drug. The mechanisms of action involve the ROS-mediated downregulation of the PI3K/Akt pathway.
\end{abstract}

\section{Introduction}

Osteosarcoma (OS) is the most common form of non-hematopoietic primary bone tumor occurring mostly in young adults and adolescents. Currently, the favored treatment for OS involves neoadjuvant chemotherapy, followed by

Correspondence to: Professor Jianmin Li, Department of Orthopedics, Qilu Hospital, Shandong University, 107 Wenhuaxi Road, Ji'nan, Shandong 250012, P.R. China

E-mail:drgkljm@163.com

Key words: osteosarcoma, diallyl trisulfide, reactive oxygen species, PI3K/Akt, apoptosis surgery and chemotherapy again, which has led to a significant improvement in the 5-year survival rate $(60-70 \%)$ in patients without metastases (1). However, 35-55\% of OS patients with initial localized disease subsequently experience recurrence. Moreover, the induction of drug resistance and the unwanted side-effects involved in chemotherapy result in inadequate treatment of the disease (2). Thus, there is an urgent need to discover new natural or synthetic compounds with the potential to prevent OS progression and improve patient survival rates.

Diallyl trisulfide (DATS) is a natural garlic extract with pungent odor and evaporability. DAT is one of the main active compounds which is a sulfide with an allyl group. Scientific investigations have shown that DATS can reduce the risk of cardiovascular disease and diabetes, stimulate the immune system and protect against infections. Meanwhile, considerable research and epidemiologic studies have revealed that DATS has broad-spectrum anti-neoplastic activity. Epidemiologic studies continue to support the premise that dietary intake of Allium vegetables, such as garlic, may be protective against the risk of certain types of cancers $(3,4)$. It can induce apoptosis of multiple cancer cells, such as those of human gastric, colon, breast and prostate cancer (5-7). It has been reported that DATS enhanced the expression of the p38 mitogen-activated protein kinase/caspase-3 signaling pathway and induced apoptosis in gastric carcinoma cell lines (5). DATS also inhibited the growth of transplanted tumor xenografts by inducing apoptosis and/or by blocking abnormal cell cycle phase (8-10), and inhibited cell migration and invasion via the downregulation of matrix metalloproteinases (MMPs) $(6,11,12)$. In addition, several studies found that reactive oxygen species (ROS) play an important role in DATS-induced death of cancer cells (13-15). However, recently, various studies have shown that DATS-induced apoptosis involves the phosphatidylinositol 3-kinase (PI3K)/Akt signaling pathways $(16,17)$. As is known, the PI3K/Akt signaling pathway is one of the most important oncogenic pathways in cancers, and is deregulated in the vast majority of localized disease and $100 \%$ of advancedstage disease in OS (18). This implies that alterations in this pathway may be a prerequisite for OS progression. Thus, numerous small-molecule compounds, particularly various natural compounds or derivatives, targeting the PI3K/Akt 
signaling pathway, have been developed and show promise for improving the survival of OS patients. Our previous studies demonstrated that DATS suppressed OS cell proliferation and reversed the drug resistance and lowered the ratio of $\mathrm{CD} 133^{+}$ cells in conjunction with methotrexate $(19,20)$. However, it is unclear whether the apoptosis induced by DATS in OS cells is related to the PI3K/Akt signaling pathway. There is little research concerning the effect of DATS on human OS cells as well as the molecular mechanism. In the present study, the effect of DATS and the possible molecular mechanism were further studied in human OS cells. Our data demonstrated that DATS induced apoptosis through the ROS-mediated downregulation of the PI3K/Akt pathway, thereby demonstrating DATS as a promising therapeutic agent for the treatment of OS.

\section{Materials and methods}

Drugs and antibodies. DATS was purchased from LKT Laboratories (St. Paul, MN, USA) and dissolved in dimethyl sulfoxide (DMSO; Sigma-Aldrich Chemical Co., St. Louis, MO, USA), and then diluted with the medium to the desired concentration prior to use. The final DMSO concentration was $<0.1 \%$ and has been verified not to interfere with the test system employed. $\mathrm{N}$-acetylcysteine (NAC) and JC-1 were purchased from Sigma-Aldrich Chemical Co. The Cell Counting Kit-8 (CCK-8) was purchased from Dojindo Molecular Technologies Inc. (Kumamoto, Japan). Annexin V-FITC and propidium iodide (PI) double staining kit was obtained from Nanjing Kaiji Biotechnology Co., Ltd. (Nanjing, China). 2,7'-Dichlorodihydrofluorescein diacetate (DCFHDA) was obtained from Jiancheng Bio-Company (Nanjing, China). Rabbit anti-human antibodies against PI3Kp110 $\beta$, PI3Kp85 $\alpha$, Bad, Bax, Bcl-xL, cytochrome $c$, caspase-9 and -3, cleaved PARP, p21, p27 and GAPDH were purchased from Abcam (Cambridge, UK). Rabbit anti-human antibodies against Akt, p-Akt (Ser473), Bcl-2, cyclin D1 and LY294002 (the PI3K inhibitor) were purchased from Cell Signaling Technology (Beverly, MA, USA). Horseradish peroxidase (HRP)-conjugated secondary antibodies against rabbit IgG were obtained from Zhongshan Jinqiao Biotechnology Co., Ltd. (Beijing, China). The enhanced chemiluminescence (ECL) detection kit (Immobilon Western Chemiluminescent HRP Substrate) was obtained from Merck Millipore (Billerica, MA, USA). All other chemicals and reagents were commercially available and of standard biochemical quality.

Cell lines and culture. Human OS cell lines MG-63 and MNNG/HOS were obtained from the American Type Culture Collection (ATCC; Rockville, MD, USA). The cells were cultured in Dulbecco's modified Eagle's medium (DMEM) containing $10 \%$ fetal bovine serum (both from Invitrogen, Carlsbad, CA, USA) in a humidified incubator with $5 \% \mathrm{CO}_{2}$ at $37^{\circ} \mathrm{C}$.

Cell viability assay and morphological observation. Cell viability was determined using the CCK-8 assay. The MG-63 and MNNG/HOS cells were seeded in 96-well plates at $1 \times 10^{4}$ cells/well in $100 \mu \mathrm{l}$ culture medium. After overnight incubation, the cells were treated with different concentrations
$(5,10,20,40,80,100$ and $120 \mu \mathrm{M})$ of DATS for 24,48 and $72 \mathrm{~h}$. CCK-8 $(10 \mu \mathrm{l})$ was added into the culture well and the cells were incubated for $2 \mathrm{~h}$ at $37^{\circ} \mathrm{C}$ with $5 \% \mathrm{CO}_{2}$ in a humidified incubator. The viability of the cells was measured by absorption at $490 \mathrm{~nm}$ using an ELISA reader (BioTek, Winooski, VT, USA). Inhibitory ratio $(\%)=(\mathrm{OD}$ control - OD treated $) / O D$ control x $100 \%$. For assessment of cell morphology after exposure to DATS, a total of $4 \times 10^{5}$ cells/well of MG63 and MNNG/ HOS cells was cultured into 6 -well plates at $37^{\circ} \mathrm{C}$ overnight, and then each well was treated with $0,20,40$ and $80 \mu \mathrm{M}$ DATS for $48 \mathrm{~h}$. The cells in each well were examined under a phasecontrast microscope and then were photographed (Olympus, Melville, NY, USA).

Flow cytometric analysis of apoptosis and cell cycle distribution. The apoptosis of the MG63 and MNNG/HOS cells was examined by flow cy tometry using Annexin V-FITC/PI staining. Briefly, the cells were cultured in 6 -well plates $\left(2 \times 10^{5}\right.$ cells/well) overnight and then were treated with the indicated concentrations $(0,20,40$ and $80 \mu \mathrm{M})$ of DATS for 24 or $48 \mathrm{~h}$. Both attached and floating cells were accumulated and washed twice with ice-cold phosphate-buffered saline (PBS; resuspended in $500 \mu \mathrm{l}$ binding buffer). The samples were treated with $5 \mu \mathrm{l}$ Annexin V-FITC and $5 \mu \mathrm{l}$ PI, and incubated at room temperature for $15 \mathrm{~min}$ in the dark. Then the cells were determined by flow cytometry (BD Calibur). For cell cycle analysis, after treatment with different concentrations $(0,20$ and $40 \mu \mathrm{M})$ of DATS for $48 \mathrm{~h}$ and fixation with $70 \%$ ice-cold ethanol overnight at $4^{\circ} \mathrm{C}$, the cells were centrifuged and treatment with RNase A ( $20 \mu 1$ in $500 \mu 1$ PBS) for $30 \mathrm{~min}$ at $37^{\circ} \mathrm{C}$. Subsequently, the cells were exposed to $400 \mu \mathrm{l} \mathrm{PI}$ and incubated at room temperature for $30 \mathrm{~min}$ in the dark and measured by flow cytometry (BD Calibur). In some groups for analysis of apoptosis and cell cycle distribution, the cells were pretreated with $5 \mathrm{mM} \mathrm{NAC}$ for $2 \mathrm{~h}$ and then co-treated with the indicated concentration of DATS for a specific time. All the data concerning apoptosis and cell cycle distribution were calculated and analyzed using FlowJo software.

Measurement of ROS. The levels of intracellular ROS in the human OS MG-63 and MNNG/HOS cells was examined using the fluorescent probe DCFH-DA. Briefly, the MG-63 and MNNG/HOS cells were seeded in 6-well plates ( $2 \times 10^{4}$ cells/well) overnight and treated with DATS $(0,20,40$ and $80 \mu \mathrm{M}$ ) and incubated for 4, 8, 16 and $24 \mathrm{~h}$, respectively. Cells were washed twice with PBS and loaded with $10 \mu \mathrm{M}$ DCFH-DA for $30 \mathrm{~min}$ in the dark. In some groups, the cells were pretreated with $5 \mathrm{mM}$ NAC for $2 \mathrm{~h}$ and then co-treated with DATS. The total level of ROS was measured by the changes in the mean fluorescence intensity (MFI) under a fluorescence microscope (Olympus) and by flow cytometric analyses (BD Calibur), respectively, (excitation wavelength, $488 \mathrm{~nm}$; emission wavelength, $530 \mathrm{~nm}$ ).

Determination of mitochondrial membrane potential $\left(\Delta \psi_{m}\right)$. The MG-63 and MNNG/HOS cells were seeded into 6-well plates $\left(2 \times 10^{5}\right.$ cells/well $)$ and incubated overnight, and then the cells were treated with $40 \mu \mathrm{M}$ DATS for $24 \mathrm{~h}$. The other cell groups were pretreated with $5 \mathrm{mM} \mathrm{NAC}$ for $2 \mathrm{~h}$ and then co-treated with $40 \mu \mathrm{M}$ DATS for $24 \mathrm{~h}$. After treatment, the 
cells were harvested and incubated with $1 \mu \mathrm{l}$ JC-1 which was diluted in $500 \mu \mathrm{l} 1 \mathrm{X}$ incubation buffer. Then, the stained cells were washed twice with $1 \mathrm{X}$ incubation buffer and resuspended in $500 \mu 11 \mathrm{X}$ incubation buffer. The fluorescent intensity was measured using flow cytometric analyses (BD Calibur). The JC-1 dye has an excitation of $488 \mathrm{~nm}$ and an emission of $530 / 590 \mathrm{~nm}$. In non-apoptotic cells, JC-1 enters the negatively charged mitochondria where it aggregates and turns red. However, in cells undergoing apoptosis, where $\Delta \psi_{\mathrm{m}}$ has collapsed, JC-1 exists as monomers in the cytosol and turns green (21). The level of $\Delta \psi_{\mathrm{m}}$ can be measured by the ratio of $\mathrm{red} / \mathrm{green}$ fluorescence intensity of JC-1. The untreated cells were the $100 \%$ MMP control.

Western blot analysis. For the preparation of cytosolic extracts, the MG-63 and MNNG/HOS cells were lysed in radioimmunoprecipitation (RIPA) buffer with $1 \mathrm{mM}$ phenylmethylsulphonyl fluoride (PMSF) for $30 \mathrm{~min}$ on ice. The mixture was centrifuged at $14,000 \mathrm{x} \mathrm{g}$ for $5 \mathrm{~min}$ and the precipitate was discarded. Protein concentration was measured with the BCA protein assay kit (Beyotime, Haimen, China). Samples containing equal amount of protein were separated by SDS-PAGE, and then transferred to polyvinylidene fluoride (PVDF) membranes (Merck Millipore) using a standard procedure. The PVDF membrane was blocked in 5\% (w/v) skim milk powder in Tris-buffered saline containing $0.1 \%$ Tween-20 for $2 \mathrm{~h}$ at room temperature. The primary antibodies against GAPDH (ab9485), PI3Kp110 $\beta$ (ab32569), PI3Kp85 $\alpha$ (ab22653) (all from Abcam), Akt (\#9272), p-Akt (Ser473) (\#9271), Bcl-2 (\#2870) (all from Cell Signaling Technology), Bcl-xL (ab2568), Bad (ab62465), Bax (ab32503), cytochrome $c$ (ab53056), caspase-9 (ab2014), caspase-3 (ab44976), cleaved PARP (ab32064) (all from Abcam), cyclin D1 (\#2978; Cell Signaling Technology), p21 (ab7960), p27 (ab7961) (both from Abcam) were diluted according to the instructions of the antibodies and incubated overnight at $4^{\circ} \mathrm{C}$. Then, the HRP-conjugated secondary antibodies were added at a dilution ratio of 1:5,000 and incubated at room temperature for $2 \mathrm{~h}$. The blots were visualized using an enhanced chemiluminescence (ECL) detection kit (WBKL S0100; Merck Millipore) according to the manufacturer's instructions. The relative protein expression levels were then determined using ChemiDoc Touch Imaging System (Bio-Rad Laboratories, Inc., Hercules, CA, USA) and quantified by Image Lab and ImageJ software. In order to quantify changes in protein expression, the target protein was normalized against GAPDH.

Statistical analysis. All the experiments were performed three times independently. All the results are expressed as the mean \pm SD. The Student's t-test by GraphPad InStat software (GraphPad Software, Inc., San Diego, CA, USA) was used to compare the difference among different groups. A $\mathrm{p}<0.05$ was considered to indicate a statistically significant result.

\section{Results}

DATS induces inhibition of cell viability and cell morphological changes. Our data showed that DATS clearly inhibited MG63 and MNNG/HOS cell viability at the concentrations of 10-120 $\mu \mathrm{M}$ following exposure for $24 \mathrm{~h}$ (Fig. 1A and B; $\mathrm{p}<0.01$ ), and 5-120 $\mu \mathrm{M}$ for 48 and $72 \mathrm{~h}$ (Fig. $1 \mathrm{~A}$ and $\mathrm{B} ; \mathrm{p}<0.01$ ) compared with the control groups. The results indicated that DATS significantly inhibited MNNG/HOS and MG63 cell viability in a dose- and time-dependent manner. The $\mathrm{IC}_{50}$ values of DATS inhibition of MG63 cell growth at 24, 48 and $72 \mathrm{~h}$ were $51.52 \pm 5.88,32.20 \pm 6.99$ and $22.02 \pm 2.33 \mu \mathrm{M}$, respectively, while the $\mathrm{IC}_{50}$ values of DATS for MNNG/HOS cell growth at 24,48 and $72 \mathrm{~h}$ were $67.17 \pm 3.69,52.34 \pm 5.67$ and $35.57 \pm 4.50 \mu \mathrm{M}$, respectively. The $48-$ and $72-\mathrm{h}$ treatment groups had apparent differences compared with the 24-h treatment groups (Fig. 1A and B; $\mathrm{p}<0.05$ ). DATS had less of an influence on MNNG/HOS cells than MG63 cells $(\mathrm{p}<0.05)$. Regarding the morphological changes of MG63 and MNNG/ HOS cells after incubation with DATS, as shown in Fig. 1C (magnification, $x 100$ ), the control group cells showed a typical polygonal and intact appearance, whereas the DATS-treated cells displayed dose-dependent changes in cell shape, such as membrane blebbing, cell rounding and shrinkage, poor adherence and floating shapes.

DATS induces cell apoptosis. The results from the flow cytometry showed that the percentage of apoptotic cells was significantly increased in the DATS treatment groups compared with that noted in the untreated MG63 and MNNG/HOS cells (Fig. 2A). After treatment with DATS at 20 and $40 \mu \mathrm{M}$ for $24 \mathrm{~h}$, and $40 \mu \mathrm{M}$ for $48 \mathrm{~h}$, the corresponding apoptotic ratios of the MG63 cells were 20.2 $\pm 2.1,27.9 \pm 1.3$ and $45.2 \pm 3.4 \%$, compared with the control group $(8.9 \pm 1.1 \%)$, while the corresponding apoptotic ratios of the MNNG/HOS cells were $15.1 \pm 1.8,25.6 \pm 1.6$ and $41.4 \pm 3.1 \%$, respectively, compared with the control group $(8.3 \pm 1.5 \%)$ (Fig. $2 \mathrm{~B} ; \mathrm{p}<0.05)$. The apoptotic ratios of both cell lines treated with DATS increased in a dose- and time-dependent manner. However, after the MG63 and MNNG/HOS cells were co-incubated with DATS $40 \mu \mathrm{M}$ and NAC $5 \mathrm{mM}$ for 24 or $48 \mathrm{~h}$, the apoptotic ratios of both cell lines were significantly decreased when compared with the corresponding DATS-treated groups (Fig. 2B; p<0.01). Co-treatment with NAC, a general ROS scavenger, completely blocked the DATS-induced apoptosis. This suggested that DATS-induced apoptosis of the MG63 and MNNG/HOS cells may be involved with the generation of ROS.

DATS induces G0/G1 phase cell cycle arrest. Results from the flow cytometry showed that the percentage of cells in the DATS-treated groups was significantly increased at the G0/G1 phase in a dose-dependent manner compared with the control groups (Fig. 3A and B; p<0.05). The percentage of G0/G1 phase cells following DATS treatment (20 and $40 \mu \mathrm{M})$ in the MG63 and MNNG/HOS cells increased from $41.7 \pm 3.4$ and $42.1 \pm 2.8$ to $52.5 \pm 4.1$ and $47.9 \pm 3.1 \%$, compared with the corresponding control groups $(33.8 \pm 2.2$ and $28.5 \pm 4.3 \%)$, respectively (Fig. 3A). These results suggested that DATSinduced G0/G1 cell cycle arrest may be one of the reasons for the inhibition of viability and the induction of apoptosis in the MG63 and MNNG/HOS cells. Furthermore, following co-treatment with DATS $(40 \mu \mathrm{M})$ and NAC, the DATS-induced G0/G1 phase arrest was completely reversed compared with the DATS-treated $(40 \mu \mathrm{M})$ groups (Fig. 3A and $\mathrm{B} ; \mathrm{p}<0.05)$. This suggested that DATS exerted its anticancer cytotoxicity 

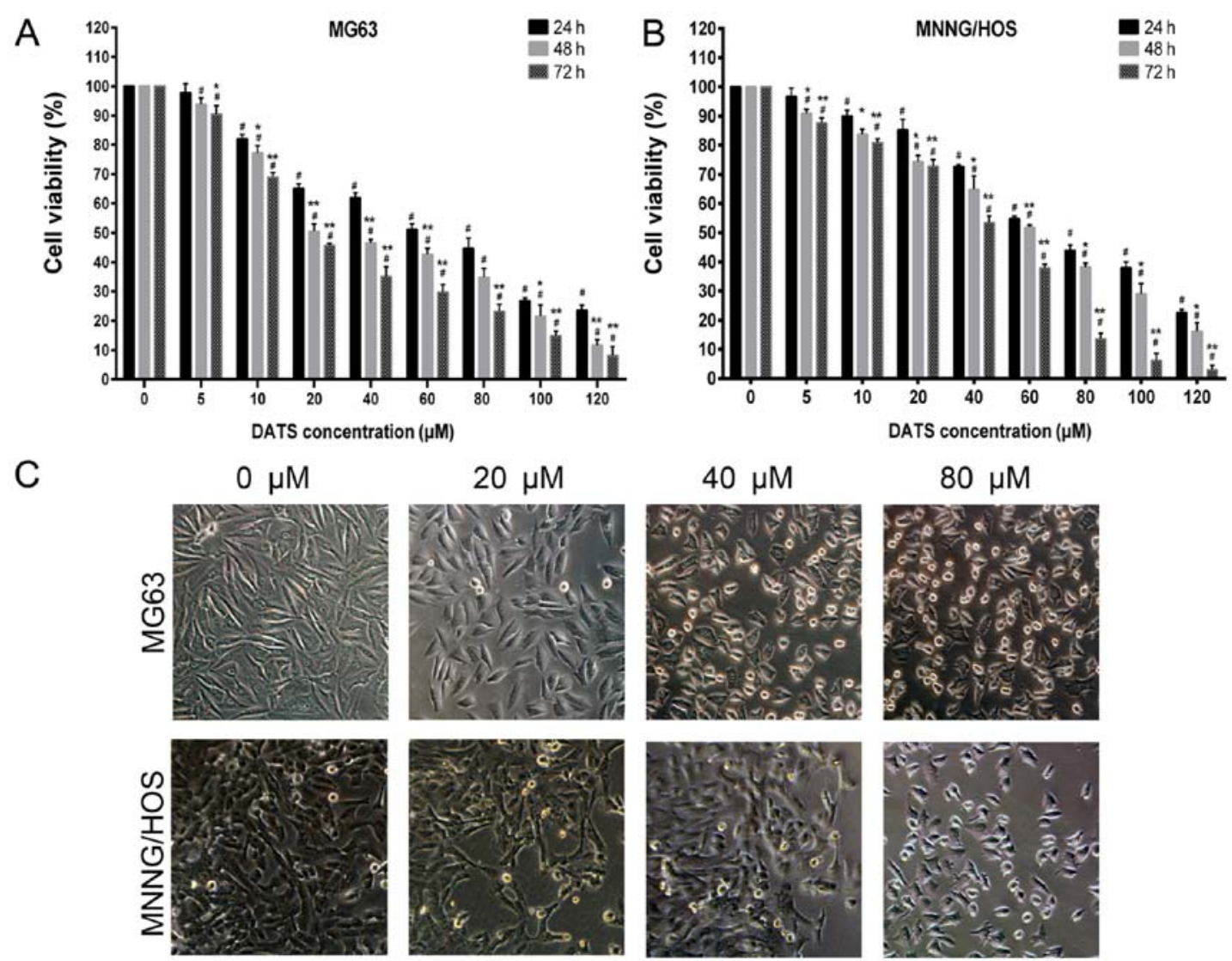

Figure 1. Effects of DATS on the cell growth inhibition of MG63 and MNNG/HOS cells. (A) MG63 and (B) MNNG/HOS cells were treated with 0, 5, 10, $20,40,60,80,100$ and $120 \mu \mathrm{M}$ of DATS for 24,48 and $72 \mathrm{~h}$. The cell growth inhibitory rate was measured using the CCK- 8 assay. The results from three independent experiments are expressed as the means $\pm \mathrm{SD}$. ${ }^{*} \mathrm{p}<0.01$ compared with the control group. ${ }^{*} \mathrm{p}<0.05,{ }^{* *} \mathrm{p}<0.01$ compared with the $24-\mathrm{h}$ group. (C) Representative morphology of the MG63 and MNNG/HOS cells, respectively, under phase contrast microscopy (magnification, x100).

A

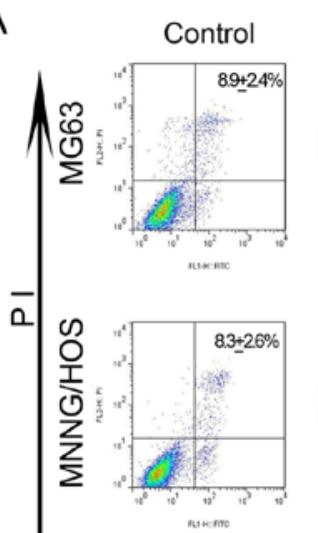

\section{B}

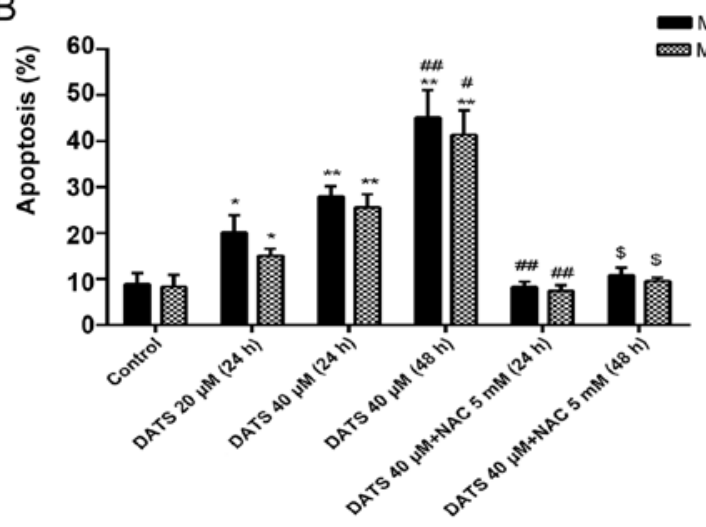

DATS $40 \mu \mathrm{M}$

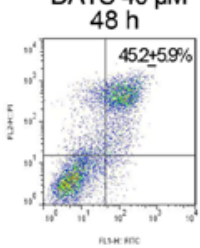

DATS 40 M +NAC $5 \mathrm{mM} 24 \mathrm{~h}$

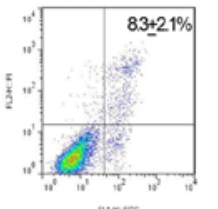

DATS $40 \mu M$
+ NAC $5 \mathrm{mM} 48$
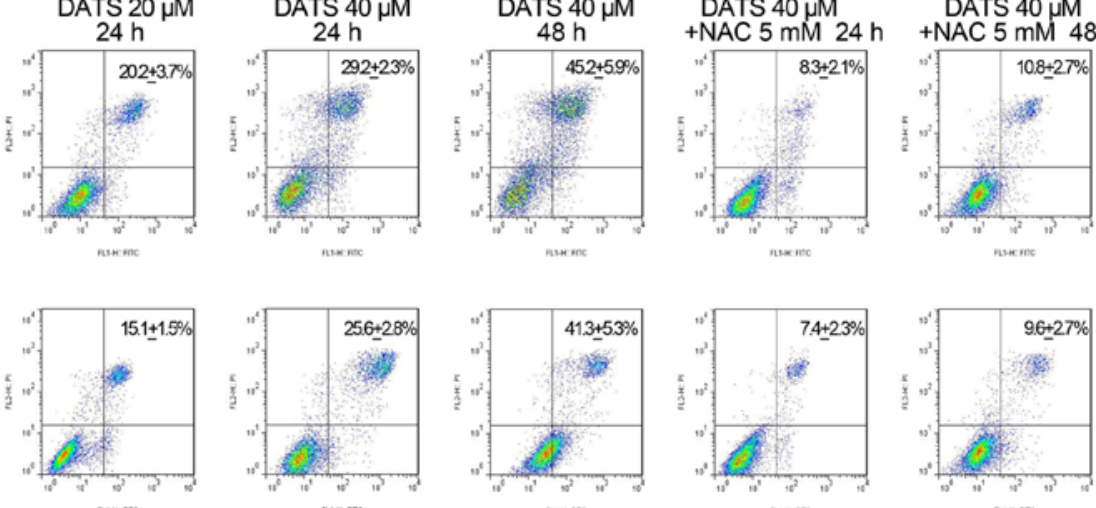

Annexin V-FITC

MG63

MNNG/HOS

Figure 2. DATS induces the apoptosis of MG63 and MNNG/HOS cells. (A) Flow cytometric analysis. (B) Cell apoptosis rate. After treatment with DATS at 20 and $40 \mu \mathrm{M}$ for $24 \mathrm{~h}, 40 \mu \mathrm{M}$ for $48 \mathrm{~h}, 40 \mu \mathrm{M}+\mathrm{NAC} 5 \mathrm{mM}$ for $24 \mathrm{~h}, 40 \mu \mathrm{M}+\mathrm{NAC} 5 \mathrm{mM}$ for $48 \mathrm{~h}$, respectively, the cells were stained with Annexin V-FITC and PI for flow cytometric analysis. The results from three independent experiments are expressed as the means $\pm \mathrm{SD}$. ${ }^{*} \mathrm{p}<0.05,{ }^{* * *} \mathrm{p}<0.01$ vs. the control group. ${ }^{\#} \mathrm{p}<0.05,{ }^{\# \#} \mathrm{p}<0.01$ compared with the DATS $40 \mu \mathrm{M} 24 \mathrm{~h}$ group. ${ }^{\$} \mathrm{p}<0.01$ compared with the DATS $40 \mu \mathrm{M} 48 \mathrm{~h}$ group. 
A
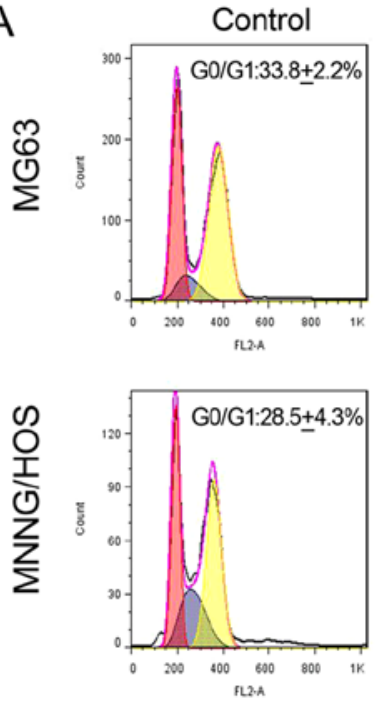

B

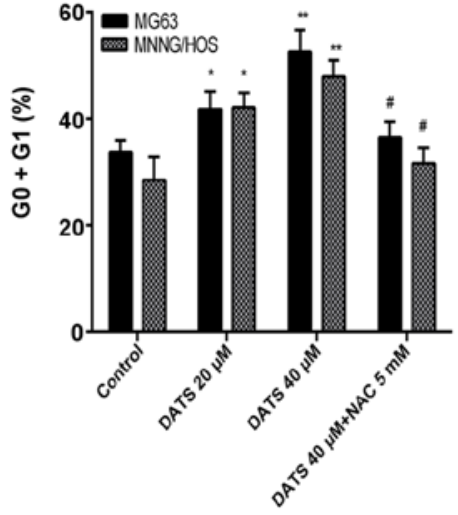

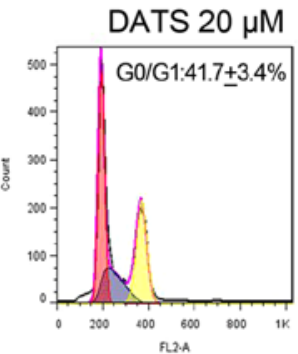

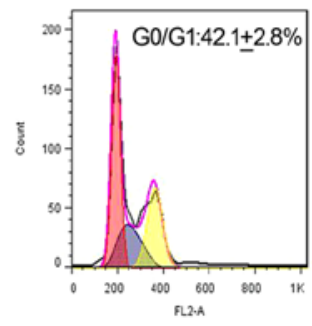

DATS $40 \mu \mathrm{M}$
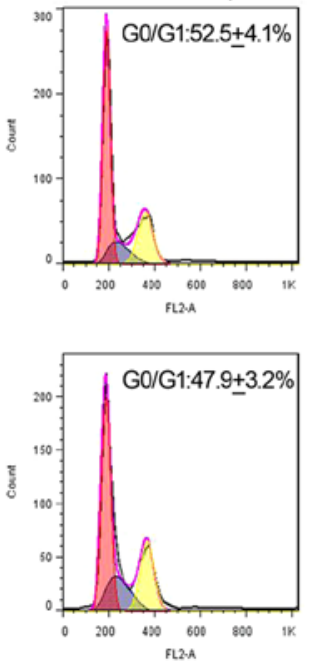

DATS $40 \mu \mathrm{M}+\mathrm{NAC} 5 \mathrm{mM}$

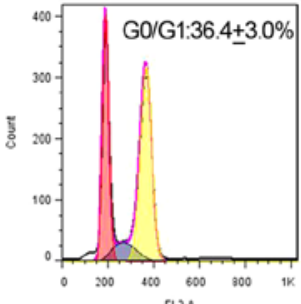

C

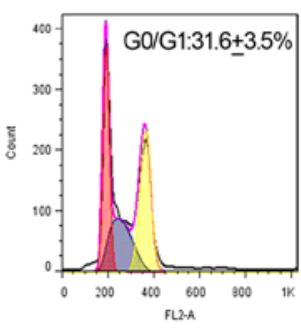

DATS $(\mu \mathrm{M})$
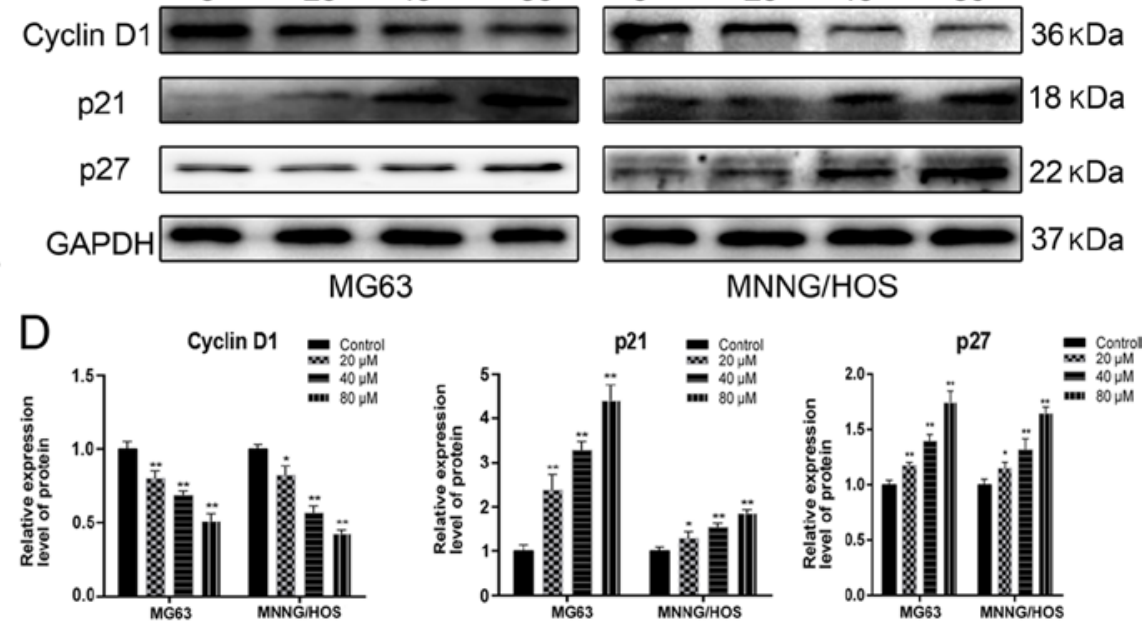

Figure 3. Effects of DATS on G0/G1 phase arrest and changes in expression of related proteins in the MG63 and MNNG/HOS cells. After treatment with DATS at 20 and $40 \mu \mathrm{M}$ for $48 \mathrm{~h}, 40 \mu \mathrm{M}+$ NAC $5 \mathrm{mM}$ for $48 \mathrm{~h}$, respectively, (A) cell cycle proportions were determined by flow cytometric analysis. (B) The percentage of cells in the G0/G1 phase. Data are expressed as the means \pm SD from three independent experiments. (C and D) Expression levels of cyclin D1, p21 and p27 detected by western blotting in the MG63 and MNNG/HOS cells treated with DATS. GAPDH was used as a loading control. Data are expressed as the means \pm SD from three independent experiments. ${ }^{*} \mathrm{p}<0.05,{ }^{* *} \mathrm{p}<0.01$ vs. the control group. ${ }^{*} \mathrm{p}<0.05$ vs. the DATS $40 \mu \mathrm{M}$ group.

through an ROS-dependent G0/G1 phase cell cycle arrest in the MG63 and MNNG/HOS cells.

To elucidate the molecular mechanism of DATS-induced G0/G1 phase arrest, we examined the expression of related proteins by western blotting. As shown in Fig. $3 \mathrm{C}$ and $\mathrm{D}$, when MG63 and MNNG/HOS cells were treated with DATS at 20, 40 and $80 \mu \mathrm{M}$ for $48 \mathrm{~h}$, a concentration-dependent decrease in levels of cyclin D1 was noted, whereas the protein levels of p21 and p27 were upregulated in a dose-dependent manner, compared with the control groups $(\mathrm{p}<0.05)$. These results suggested that DATS-induced G0/G1 phase arrest of the MG63 and MNNG/HOS cells involved the generation of ROS and the downregulation of cyclin D1 and upregulation of p21 and p27.

DATS increases the generation of ROS. To explore the induction of intracellular ROS generation by DATS, we quantified the MFI of cells stained with DCFH-DA by FlowJo and ImageJ software in the MG63 and MNNG/HOS cells. Our results from fluorescence microscopy revealed that the levels of ROS in the DATS treatment cells for 4 and $8 \mathrm{~h}$ were not significantly altered, whereas the green fluorescence was markedly elevated following $16 \mathrm{~h}$ of treatment with DATS compared with those of the control groups (Fig. 4A; magnification, x100). Sixteen hours of treatment of DATS at 20, 40 and $80 \mu \mathrm{M}$ enhanced the ROS level by 2.7-, 4.4- and 5.4-fold of the control groups, respectively, in the MG63 cells, and 5.0-, 8.1- and 11.4-fold of the control groups, respectively, in the MNNG/HOS cells (Fig. 4C; $\mathrm{p}<0.01)$. When the cells were co-treated with DATS at 40 or $80 \mu \mathrm{M}$ and NAC $5 \mathrm{mM}$ for $16 \mathrm{~h}$, the intracellular ROS generation was reversed compared with that noted in the DATS-treated groups (Fig. 4A and C; $\mathrm{p}<0.01$ ). The intracellular ROS generation increased in a dose-dependent manner in the DATS-treated cells. Furthermore, we examined the intracellular ROS level by flow cytometric analyses in the DATS-treated cells at $40 \mu \mathrm{M}$ for $16 \mathrm{~h}, 20 \mu \mathrm{M}$ for $24 \mathrm{~h}$ and $40 \mu \mathrm{M}$ for $24 \mathrm{~h}$, respectively. As shown in Fig. 4B and D, the intracellular ROS generation in the DATS-treated cells increased in a dose- and time-dependent manner compared to the control groups $(\mathrm{p}<0.05)$. However, 
A
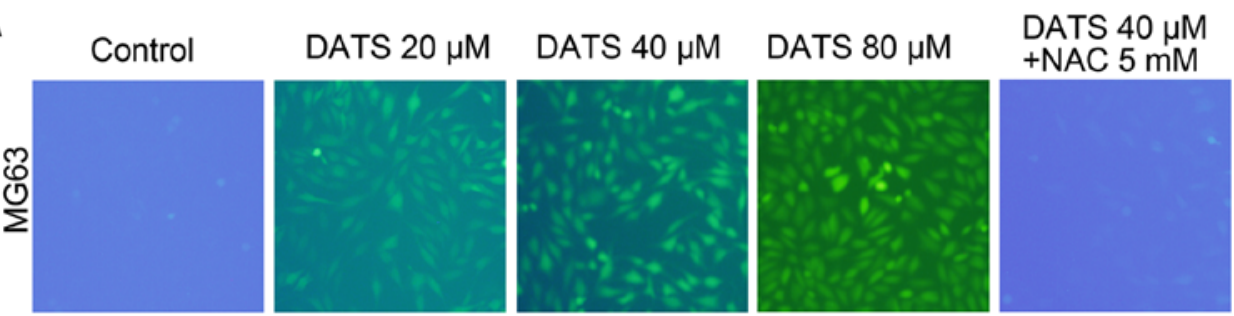

DATS $80 \mu \mathrm{M}$
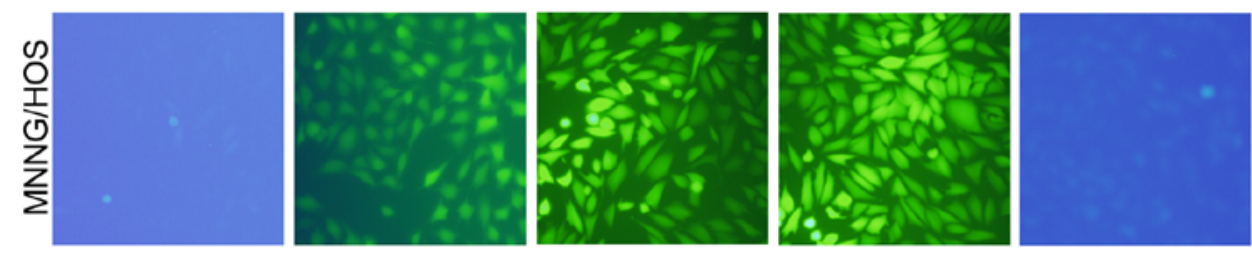

B
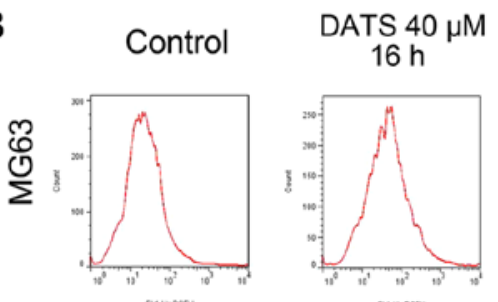

DATS $20 \mu \mathrm{M}$

DATS $40 \mu \mathrm{M}$

DATS $40 \mu \mathrm{M}$ $16 \mathrm{~h}$ $24 \mathrm{~h}$
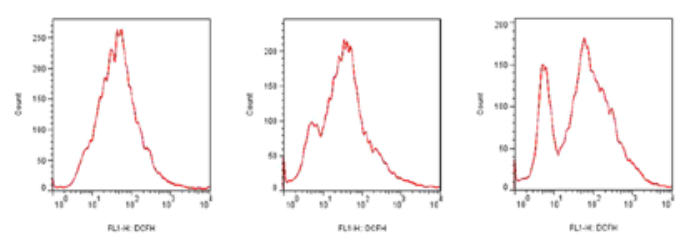

$+\mathrm{NAC} 5 \mathrm{mM} 24 \mathrm{~h}$
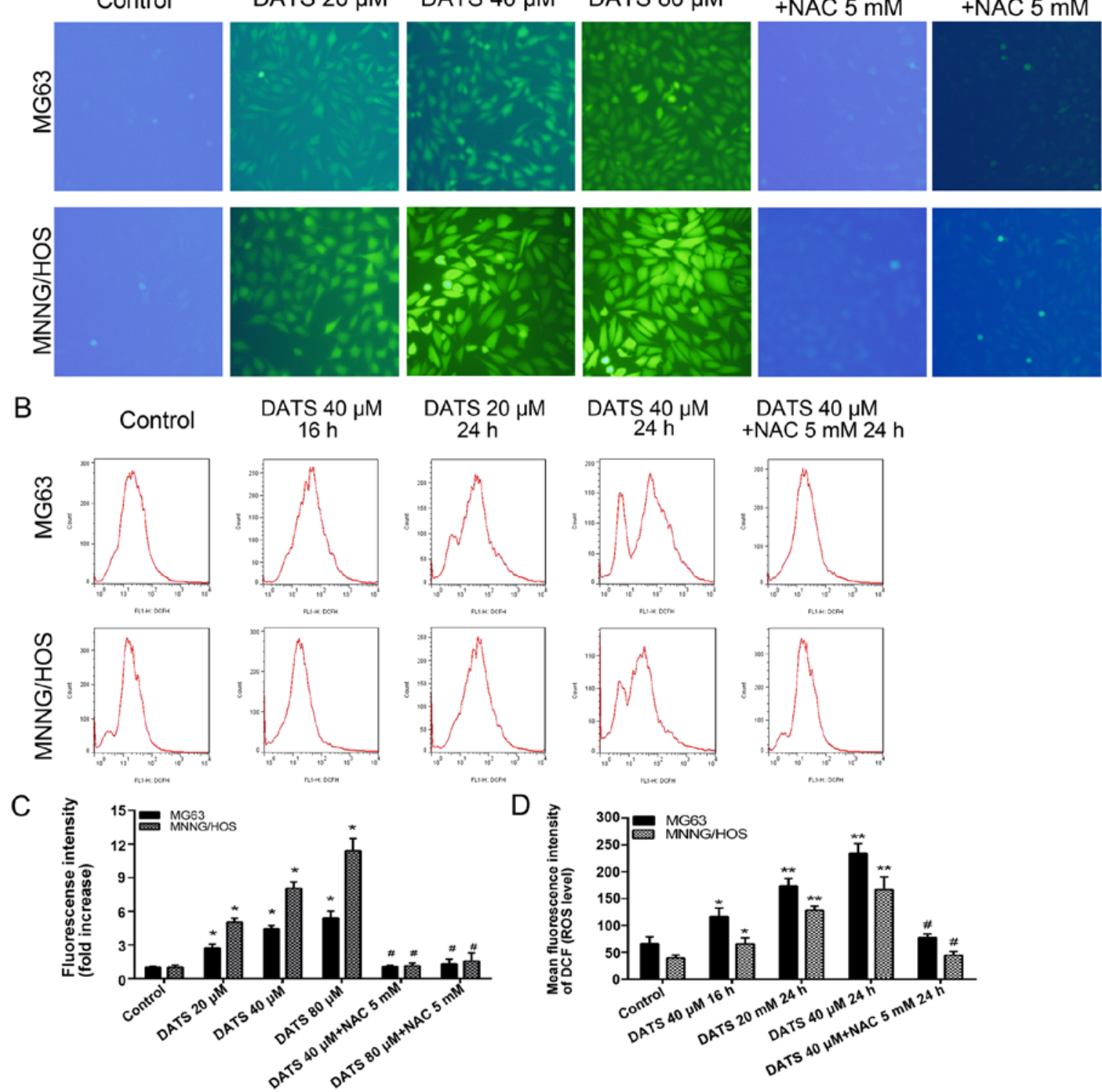

Figure 4. DATS increases the generation of intracellular ROS in the MG63 and MNNG/HOS cells. (A) After treatment with DATS at 20,40 and $80 \mu \mathrm{M}$, $40 \mu \mathrm{M}+\mathrm{NAC} 5 \mathrm{mM}, 80 \mu \mathrm{M}+\mathrm{NAC} 5 \mathrm{mM}$ for $16 \mathrm{~h}$, respectively, the cells were loaded with $10 \mu \mathrm{M}$ DCFH-DA for 30 min and examined by a fluorescence microscope (magnification, x100). (B) After treatment with DATS at $40 \mu \mathrm{M}$ for $16 \mathrm{~h}, 20,40$ and $40 \mu \mathrm{M}+\mathrm{NAC} 5 \mathrm{mM}$ for $24 \mathrm{~h}$, respectively, the cells were loaded with $10 \mu \mathrm{M}$ DCFH-DA for flow cytometric analysis. (C) The fluorescence intensity (ROS level) from fluorescence microscopy was quantified by ImageJ software. (D) The mean fluorescence intensity (ROS level) from flow cytometric analysis. Data are expressed as the means \pm SD from three independent experiments. ${ }^{*} \mathrm{p}<0.05,{ }^{* *} \mathrm{p}<0.01$ vs. the control group. ${ }^{*} \mathrm{p}<0.01$ vs. the corresponding DATS treatment groups.

co-treatment with DATS $(40 \mu \mathrm{M})$ and NAC $(5 \mathrm{mM})$ completely blocked the increase in intracellular ROS compared with the DATS $(40 \mu \mathrm{M})$-treated groups in the MG63 and MNNG/HOS cells (Fig. 4B and D; $\mathrm{p}<0.01$ ).

DATS induces disruption of $\Delta \psi_{m}$. As can be seen in Fig. 5A and B, after the MG63 and MNNG/HOS cells were treated with DATS at $40 \mu \mathrm{M}$ for $24 \mathrm{~h}$, the ratio of red/green fluorescence intensity $\left(\Delta \psi_{\mathrm{m}}\right.$ level $)$ decreased 31.3 and $39.1 \%$, respectively, compared with control groups $(\mathrm{p}<0.01)$. To investigate whether the increase in ROS induced by DATS mediated mitochondrial damage, the cells were co-treated with DATS and NAC. The results showed that NAC significantly restored the $\Delta \psi_{\mathrm{m}}$ level compared with DATS-treated cells (Fig. 5; $\mathrm{p}<0.05)$. This suggested that the disruption of $\Delta \psi_{\mathrm{m}}$ induced by DATS was ROS-dependent.

DATS induces apoptosis through ROS-mediated downregulation of the PI3K/Akt and mitochondrial apoptotic pathways. To assess whether DATS-induced apoptosis was affected by PI3K/Akt pathway inactivation, MG63 and MNNG/HOS cells were treated with various concentrations of DATS $(0,20,40$ and $80 \mu \mathrm{M})$ for $48 \mathrm{~h}$ and analyzed by western blotting. As shown in Fig. 6A-C, DATS reduced the expression levels of PI3Kp110 $\beta$, PI3Kp85 $\alpha$, Akt and p-Akt in a concentration-dependent manner compared with these levels in the untreated cells $(\mathrm{p}<0.05)$. In addition, we investigated the downstream target involvement of the PI3K/Akt pathway. As 

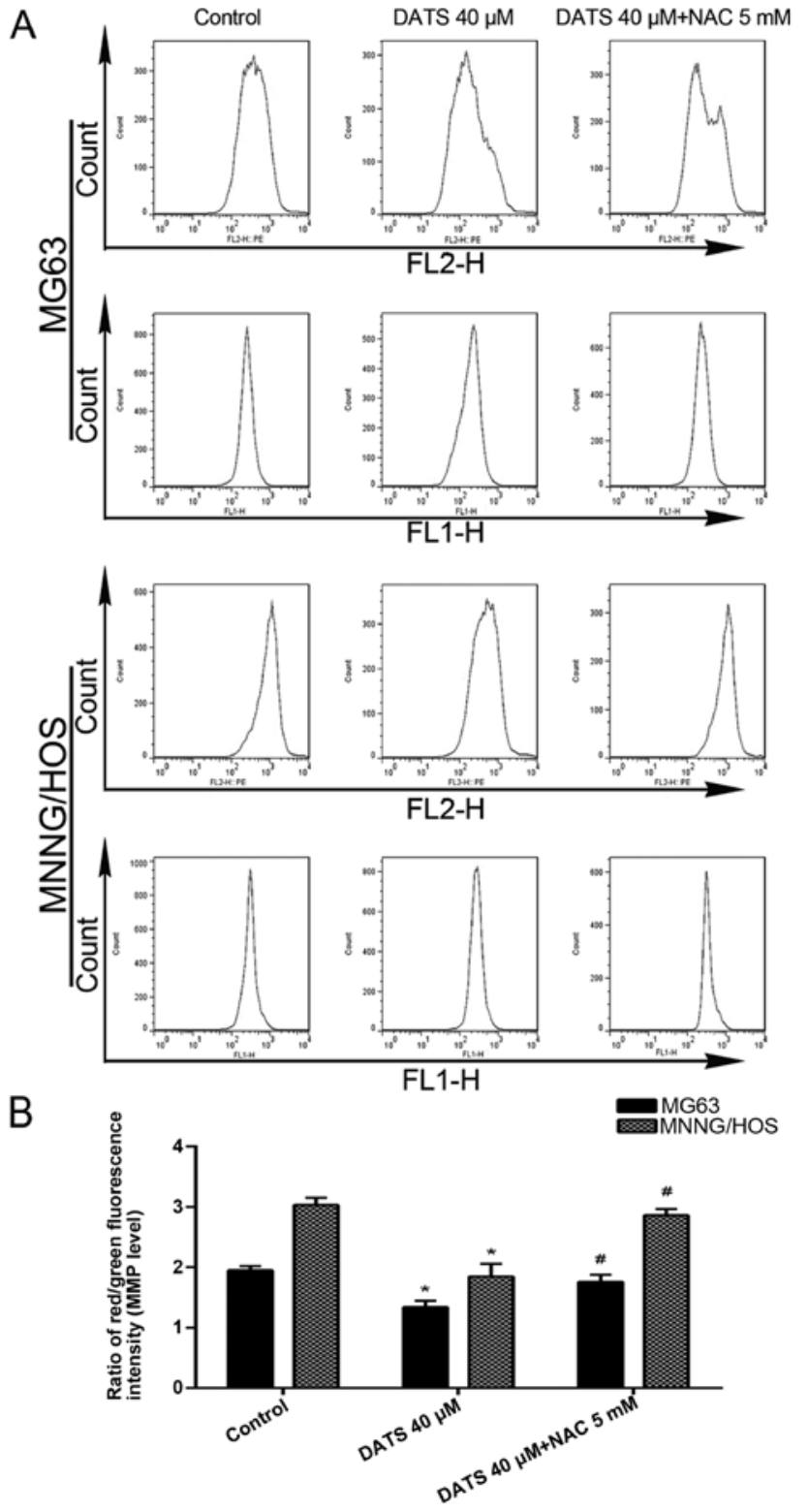

Figure 5. DATS induces disruption of mitochondrial membrane potential $\left(\Delta \psi_{\mathrm{m}}\right)$ in the MG63 and MNNG/HOS cells. (A) The cells were treated with DATS $40 \mu \mathrm{M}$ or co-treated with DATS $40 \mu \mathrm{M}$ and NAC $5 \mathrm{mM}$ for $24 \mathrm{~h}$, and the fluorescence value of red and green was determined by flow cytometry after staining with JC-1. (B) The histogram shows the ratio of red/green fluorescence intensity $\left(\Delta \psi_{\mathrm{m}}\right.$ level) in the MG63 and MNNG/HOS cells. Data are expressed as the means \pm SD from three independent experiments. " $p<0.05$ vs. the control group. ${ }^{\#} \mathrm{p}<0.05$ vs. the DATS $40 \mu \mathrm{M}$ group.

shown in Fig. 6A, D and E, the levels of Bcl-2 and Bcl-xL proteins were decreased, whereas the expression levels of Bad and Bax were increased in response to DATS treatment in a concentration-dependent manner when compared with these levels in the control groups $(\mathrm{p}<0.05)$. These results are consistent with previously reported studies $(16,22)$. Our present study showed that DATS-induced apoptosis involved an increase in intracellular ROS and mitochondrial damage, which led to loss of $\Delta \psi_{\mathrm{m}}$ level. This suggests that the mitochondrial apoptotic pathway may play a pivotal role in DATS-induced apoptosis. To reveal the mechanisms underlying the apoptotic effect of DATS on MG63 and MNNG/HOS cells, we further investigated the expression levels of cytochrome $c$, caspase-9 and -3 in the DATS-treated cells. As shown in Fig. 6A, F and G, after treatment with DATS at 20,40 and $80 \mu \mathrm{M}$ for $48 \mathrm{~h}$, the levels of cytochrome $c$, caspase- 9 and -3 were upregulated in a dose-dependent manner, respectively, compared with these levels in the control groups $(\mathrm{p}<0.05)$. In addition, DATS treatment led to progressive proteolytic cleavage of poly(ADP-ribose) polymerase (PARP), a well-known substrate protein of activated caspase-3. Taken together, caspase-9 upregulation by DATS demonstrated an association of DATS-induced apoptosis with the intrinsic or mitochondrial-dependent pathway.

To further test the contribution of the PI3K/Akt pathway in DATS-induced apoptosis, LY294002, a specific PI3K inhibitor, was used. The MG63 and MNNG/HOS cells were treated with DATS $(40 \mu \mathrm{M})$ or LY294002 $(20 \mu \mathrm{M})$ or co-treated with DATS $(40 \mathrm{mM})$ and LY294002 $(20 \mu \mathrm{M})$ for $48 \mathrm{~h}$. As shown in Fig. 7, the levels of PI3Kp110 $\beta$, PI3Kp85 $\alpha$, Akt and p-Akt were significantly decreased with respect to those in the presence of either DATS or LY294002, and the combined treatment groups showed a more powerful synergistic effect to trigger apoptosis compared with either treatment alone in the MG63 and MNNG/HOS cells ( $\mathrm{p}<0.05$ ). Meanwhile, the downstream proteins, Bad and Bax were upregulated whereas Bcl-2 and $\mathrm{Bcl}-\mathrm{xL}$ were downregulated in the treated alone groups or the combined treatment groups compared with the control groups $(\mathrm{p}<0.01)$. In addition, as expected, the expression changes in proteins of the Bcl-2 family in the combined treatment groups were enhanced compared with the single factor treatment groups. We found that DATS served as an inhibitor of the PI3K/Akt pathway in DATS-induced apoptosis.

To investigate the relationship between the increase of ROS and inhibition of the PI3K/Akt pathway in DATS-induced apoptosis, the MG63 and MNNG/HOS cells were treated with DATS $(40 \mu \mathrm{M})$ for $48 \mathrm{~h}$, in the absence or presence of NAC $(5 \mathrm{mM})$. Previous studies have shown that NAC, a common ROS scavenger, has no effect on cell viability and apoptosis induction at the concentration of $10 \mathrm{mM}$ (14). The western blot data (Fig. 7A-C), showed that the presence of NAC almost completely blocked DATS-induced downregulation of the PI3K/Akt pathway $(\mathrm{p}<0.05)$. In addition, the changes in the protein expression of the Bcl-2 family (upregulation of $\mathrm{Bad}$ and Bax, downregulation of Bcl-2 and Bcl-xL) were completely abrogated by NAC compared with the DATS $(40 \mu \mathrm{M})$-treated groups (Fig. 7A, D and E; p<0.05).

\section{Discussion}

In previous studies, the anticancer effect of diallyl trisulfide (DATS) was mainly restricted to malignant tumor cells of the digestive, reproductive or hematological system, while research on the effect and mechanism of DATS against osteosarcoma (OS) is rare. In the present study, to the best of our knowledge, this is the first study to report that DATS induced MG63 and MNNG/HOS cell proliferation inhibition, increased apoptosis, G0/G1 phase arrest and mitochondrial damage. The possible molecular mechanism by which DATS induced apoptosis involved inhibition of the PI3K/Akt signaling pathway, which was dependent on the generation of ROS.

In the present study, our experiments revealed that DATS inhibited the viability and proliferation of MG63 and 
A

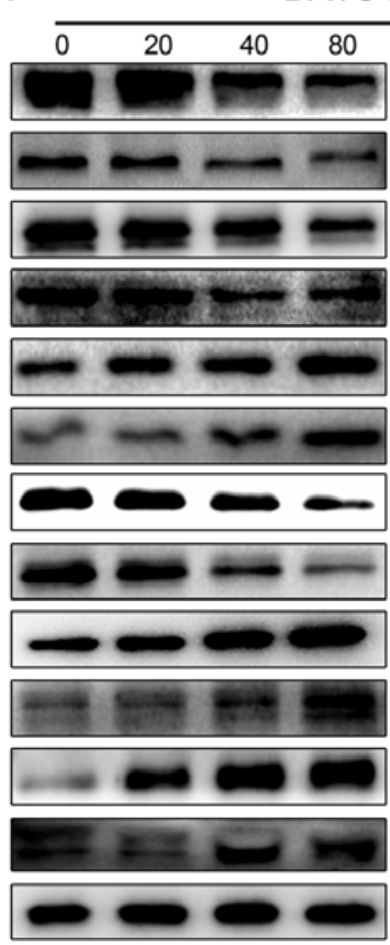

MG63
$\operatorname{DATS}(\mu \mathrm{M})$

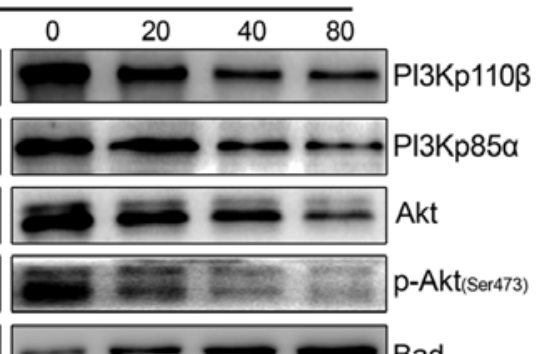

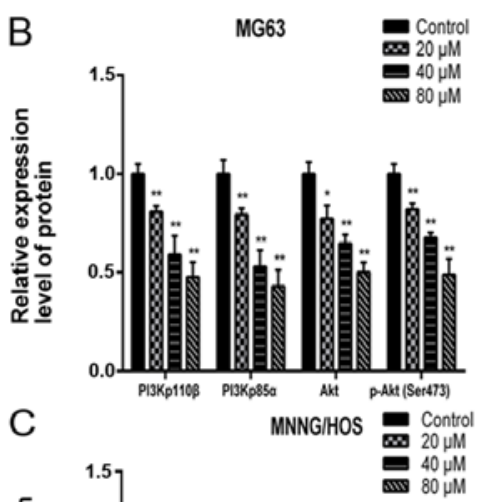
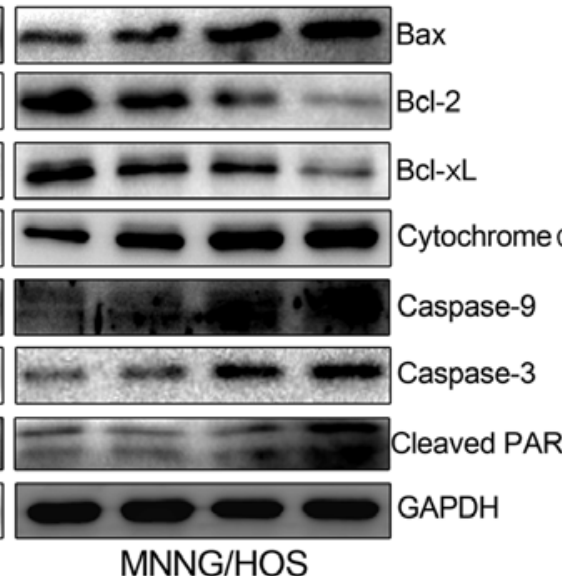

MNNG/HOS
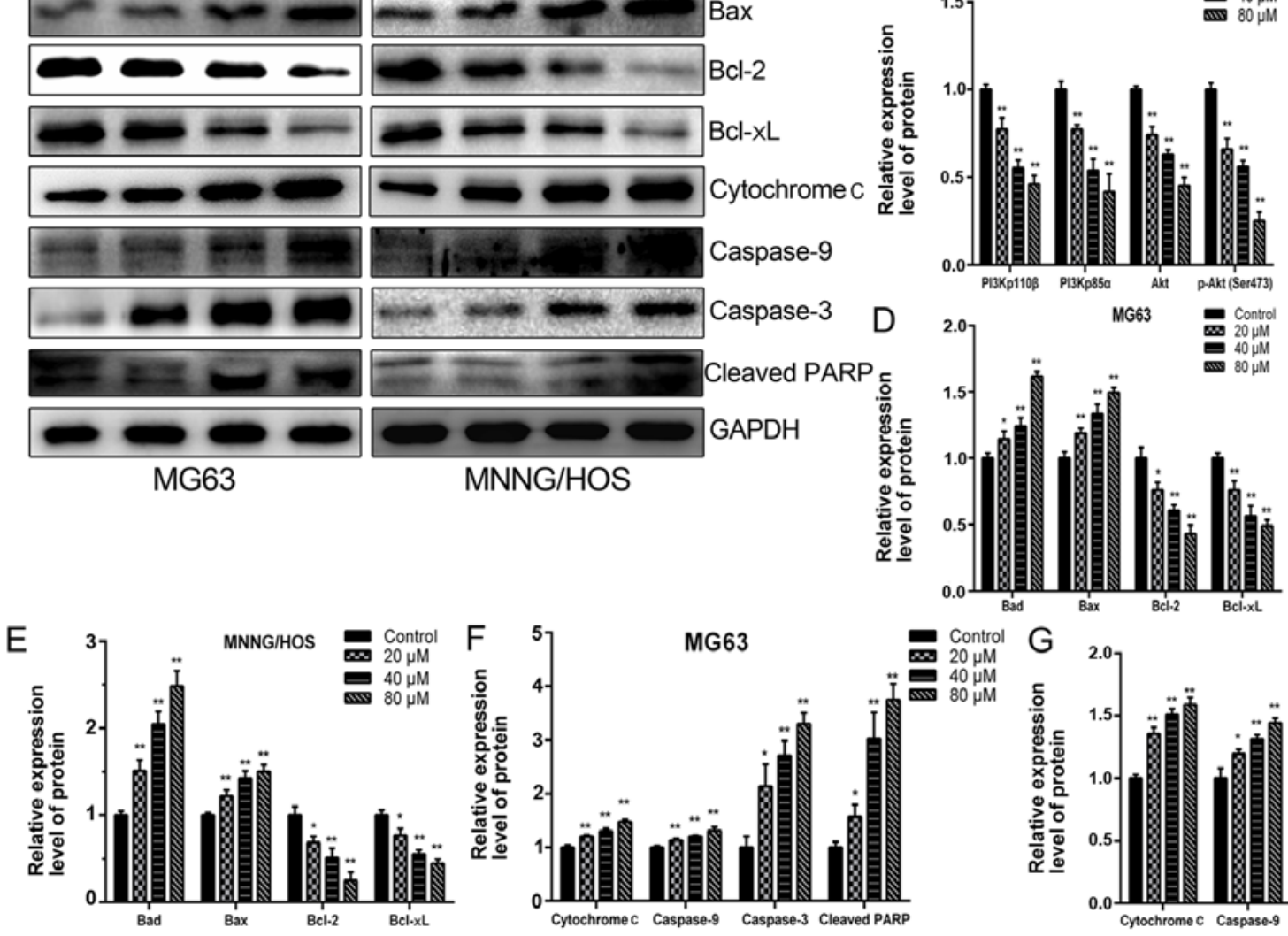

Figure 6. DATS induces apoptosis via inhibition of the PI3K/Akt signaling axis and through the mitochondrial apoptotic pathway in the MG63 and MNNG/HOS cells. The cells were treated with DATS at $0,20,40$ and $80 \mu \mathrm{M}$ for $48 \mathrm{~h}$, and protein expression levels were determined by western blotting and quantified by densitometric analysis. (A) Representative blots. Relative expression levels of (B and C) PI3Kp110 $\beta$, PI3Kp85a, Akt, p-Akt (Ser473), (D and E) Bad, Bax, Bcl-2, Bcl-xL (F and G) cytochrome $c$, caspase-9 and caspase-3, cleaved PARP in the DATS-treated MG63 and MNNG/HOS cells. GAPDH was used as a loading control. Data are expressed as the means $\pm \mathrm{SD}$ from three independent experiments. ${ }^{*} \mathrm{p}<0.05,{ }^{* *} \mathrm{p}<0.01$ vs. the control group.

MNNG/HOS cells in a dose- and time-dependent manner, which was in agreement with previous research $(5,16,23)$. Furthermore, our results showed that DATS is capable of triggering apoptosis in MG63 and MNNG/HOS cells in a dose- and time-dependent manner, which was consistent with previous research $(9,16,23)$. Apoptosis is a highly regulated physiologic process, which is carried out mainly through two key pathways: the death receptor-mediated pathway (extrinsic pathway) and the mitochondrial-initiated apoptotic pathway (intrinsic pathway). The mitochondria play a central role in apoptosis regulation by releasing cytochrome $c$ into the cytoplasm, leading to the activation of the caspase-cascade system (24). We also investigated the effect of DATS on the cell cycle by flow cytometry, and the results showed that DATS induced G0/G1 phase cell cycle arrest in a dose-dependent manner in the MG63 and MNNG/HOS cells, which is consistent with previous research (25). Notably, various previous studies have reported that DATS induced G2/M phase cell cycle arrest (lung, skin and pancreas cancer cells) (26-28), and these contradictory results appear to indicate that DATS exerts a differential effect in a cell type-specific manner. Furthermore, we examined the cell cycle-related protein expression to elucidate the underlying mechanism of DATSinduced G0/G1 phase arrest. Cyclin D1, which belongs to the cyclin D family, is required for cell cycle G1/S transition. Overexpression of cyclin D1 is known to correlate with the risk of tumor progression (29). The p21 and p27 genes have recently been discovered to be important cyclin-dependent kinase inhibitors (CDKIs) and regulate the cell cycle as well as DNA replication and repair (30). Our results found that the expression of cyclin D1 was decreased whereas levels of p21 and p27 were upregulated. This is the first study to report the 


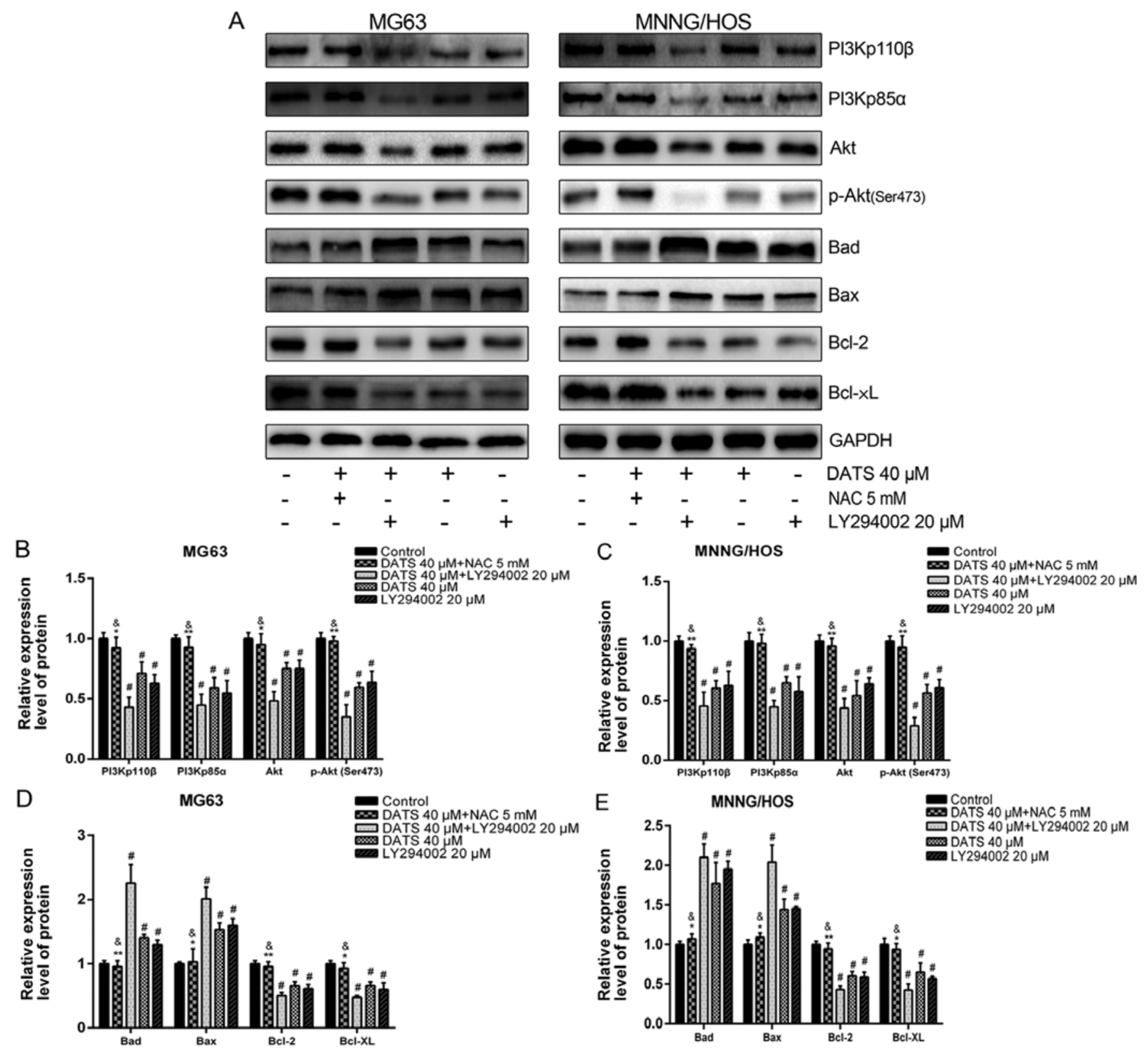

Figure 7. ROS-dependent inhibition of the PI3K/Akt signaling pathway is involved in DATS-induced apoptosis. The MG63 and MNNG/HOS cells were pretreated with $5 \mathrm{mM} \mathrm{NAC}$ for $2 \mathrm{~h}$, and then co-treated with $40 \mu \mathrm{M}$ DATS for $48 \mathrm{~h}$; other groups were treated with $40 \mu \mathrm{M}$ DATS or $20 \mu \mathrm{M}$ LY294002, or co-treated with $40 \mu \mathrm{M}$ DATS $+20 \mu \mathrm{M} \mathrm{LY} 294002$ for $48 \mathrm{~h}$. Protein expression levels were determined by western blotting and quantified by densitometric analysis. (A) Representative blots. Relative expression levels of (B and C) PI3Kp110 $\beta$, PI3Kp85a, Akt, p-Akt (Ser473), (D and E) Bad, Bax, Bcl-2, Bcl-xL in the DATS-treated MG63 and MNNG/HOS cells. GAPDH was used as a loading control. Data are expressed as the means \pm SD from three independent experiments. ${ }^{*} \mathrm{p}<0.01$ vs. the control group. ${ }^{*} \mathrm{p}<0.05,{ }^{* *} \mathrm{p}<0.01$ vs. the DATS $40 \mu \mathrm{M}$ group, ${ }^{\star} \mathrm{p}>0.05$ vs. the control group.

possible mechanism of DATS-induced G0/G1 phase arrest to date. However, surprisingly, co-treatment with antioxidant NAC completely blocked the DATS-induced apoptosis and G0/G1 phase arrest, which suggests that DATS exerted its anticancer cytotoxicity through an ROS-dependent manner in the MG63 and MNNG/HOS cells.

ROS, various small, short-lived and highly reactive molecules, are well known mediators of intracellular cascade signaling. It has been reported that ROS generation plays a crucial role in the pro-apoptotic activities of various anticancer agents (31-33). The oxidative stress damage leads to mitochondrial dysfunction, disruption of $\Delta \psi_{\mathrm{m}}$, ultimately resulting in cell apoptosis. The present study showed that the level of ROS increased whereas the $\Delta \psi_{\mathrm{m}}$ collapsed significantly in the DATS-treated cells. However, co-treatment of NAC significantly restored the level of ROS and $\Delta \psi_{\mathrm{m}}$ compared with the DATS-treated cells, suggesting that the disruption of $\Delta \psi_{\mathrm{m}}$ induced by DATS was ROS-dependent. Several studies have reported the critical roles of ROS in DATS-induced cell apoptosis, such as ROS-mediated activation of JNK and AP-1 in breast cancer cells (34), the ROS-dependent caspase pathway in leukemia cells (14), and ROS-dependent activation of the ASK1-JNK-Bim signaling transduction pathway in human breast carcinoma cells (35). These controversial 


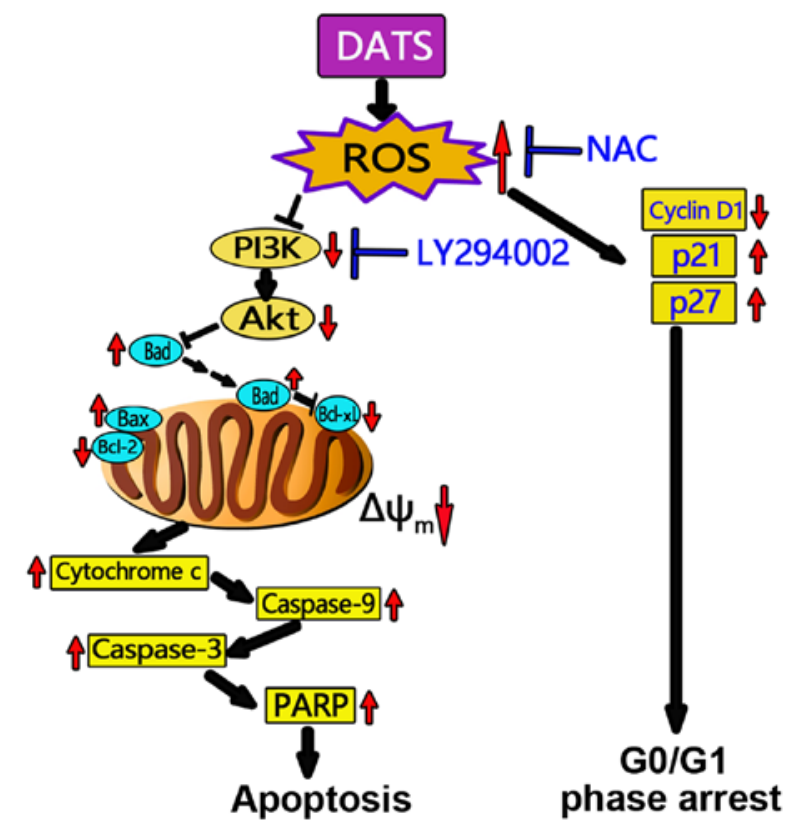

Figure 8. Proposed model of DATS-induced migration and invasion inhibition, cell cycle arrest and apoptosis in the human osteosarcoma MG63 and MNNG/HOS cells. The arrows indicate the expression changes as determined in our results.

mechanisms again raise the possibility that DATS may affect different signaling pathways according to cell type or culture condition. In the present study, we demonstrated that DATSstimulated ROS generation may play a significant upstream role by targeting various cancer-associated proteins and may contribute to DATS-induced apoptosis in OS cells. We found the downregulation of PI3K, Akt, p-Akt in a dose-dependent manner in the DATS-treated MG63 and MNNG/HOS cells, a finding corroborated by several previous studies $(16,17)$. The PI3K/Akt signaling pathway, which plays a critical role in controlling the balance between cell survival and apoptosis, is abnormally activated in a wide variety of cancers and results in enhanced resistance to apoptosis through multiple mechanisms, and therefore, they are prime targets for cancer therapy (36). Cells overexpressing constitutively active Akt show a much higher resistance to drug-induced cell death (37). In addition, activated Akt protects cells against apoptosis by increasing the phosphorylation of Bad, a pro-apoptotic Bcl-2 family member which promotes cell death by competing with $\mathrm{Bcl}-2 / \mathrm{Bcl}-\mathrm{xL}$ in binding to $\mathrm{Bax}$ (38). A decrease in $\Delta \psi_{\mathrm{m}}$ level and an unbalance between pro-apoptotic (Bad and Bax) and anti-apoptotic (Bcl-2 and Bcl-xL) members of the Bcl-2 family cause mitochondrial permeability transition and contribute to the release of cytochrome $c$, which in turn activates caspase-9 and downstream caspase-3. Active capase-3 promotes a cascade reaction including degradation of PARP finally leading to apoptosis. In the present study, DATS induced the downregulation of Bcl-2 and Bcl-xL, as well as the upregulation of Bad, Bax, cytochrome $c$, caspase-9, and -3 and cleaved PARP, which provided evidence for a direct contribution of mitochondria in DATS-induced apoptosis.

Furthermore, to investigate the effect of ROS induced by DATS on the PI3K/Akt pathway and contribution of the PI3K/ Akt pathway in DATS-induced apoptosis, a specific phar- macological inhibitor of PI3K/Akt, LY294002, and an ROS scavenger, NAC, were used in the MG63 and MNNG/HOS cells. The results revealed that DATS effectively inhibited the PI3K/Akt pathway, and the efficiency of DATS basically approached the efficacy of LY294002. However, complete blockage of DATS-induced apoptosis and inhibition of the PI3K/Akt pathway by NAC treatment highlighted a possible mechanism - an increase in ROS induced by DATS was a key step required for inhibition of the PI3K/Akt pathway in the MG63 and MNNG/HOS cells.

In conclusion, the present study demonstrated that DATS exerted cytotoxic and antiproliferative effects on human OS MG63 and MNNG/HOS cells. DATS induced an increase in intracellular ROS and collapse of $\Delta \psi_{\mathrm{m}}$, thus further inducing MG63 and MNNG/HOS cell apoptosis and G0/G1 phase cell cycle arrest. DATS-induced apoptosis in the MG63 and MNNG/HOS cells was mediated by inactivation of the PI3K/Akt signaling axis and through the mitochondrial apoptotic pathway, which was ROS-dependent (Fig. 8). Our data emphasize the key role of ROS in the apoptosis induced by DATS and indicates that a positive correlation exists between ROS and the PI3K/Akt signaling pathway as well as mitochondrial events leading to apoptosis in the MG63 and MNNG/ HOS cells. Our novel findings shed new light on the molecular mechanisms of the inhibitory effects of DATS on the growth of cancer cells, and raise the possibility of DATS as a potential anticancer and/or cancer preventive agent.

\section{Acknowledgements}

The present study was supported by the National Natural Scientific Foundation of China (81172551) and the Shandong Technological Development Project (ZR2011HM037).

\section{References}

1. Bielack SS, Kempf-Bielack B, Delling G, Exner GU, Flege S, Helmke K, Kotz R, Salzer-Kuntschik M, Werner M, Winkelmann W, et al: Prognostic factors in high-grade osteosarcoma of the extremities or trunk: An analysis of 1,702 patients treated on neoadjuvant cooperative osteosarcoma study group protocols. J Clin Oncol 20: 776-790, 2002.

2. Boos G and Stopper H: Genotoxicity of several clinically used topoisomerase II inhibitors. Toxicol Lett 116: 7-16, 2000.

3. Fleischauer AT, Poole C and Arab L: Garlic consumption and cancer prevention: Meta-analyses of colorectal and stomach cancers. Am J Clin Nutr 72: 1047-1052, 2000.

4. Hsing AW, Chokkalingam AP, Gao YT, Madigan MP, Deng J, Gridley $G$ and Fraumeni JF Jr: Allium vegetables and risk of prostate cancer: A population-based study. J Natl Cancer Inst 94: 1648-1651, 2002.

5. Zhang X, Zhu Y, Duan W, Feng C and He X: Allicin induces apoptosis of the MGC-803 human gastric carcinoma cell line through the p38 mitogen-activated protein kinase/caspase-3 signaling pathway. Mol Med Rep 11: 2755-2760, 2015.

6. Lai KC, Hsu SC, Yang JS, Yu CC, Lein JC and Chung JG: Diallyl trisulfide inhibits migration, invasion and angiogenesis of human colon cancer HT-29 cells and umbilical vein endothelial cells, and suppresses murine xenograft tumour growth. J Cell Mol Med 19: 474-484, 2015.

7. Chandra-Kuntal K and Singh SV: Diallyl trisulfide inhibits activation of signal transducer and activator of transcription 3 in prostate cancer cells in culture and in vivo. Cancer Prev Res 3: 1473-1483, 2010.

8. Wu PP, Liu KC, Huang WW, Chueh FS, Ko YC, Chiu TH, Lin JP, Kuo JH, Yang JS and Chung JG: Diallyl trisulfide (DATS) inhibits mouse colon tumor in mouse CT-26 cells allograft model in vivo. Phytomedicine 18: 672-676, 2011. 
9. Li W, Tian H, Li L, Li S, Yue W, Chen Z, Qi L, Hu W, Zhu Y, Hao B, et al: Diallyl trisulfide induces apoptosis and inhibits proliferation of A549 cells in vitro and in vivo. Acta Biochim Biophys Sin 44: 577-583, 2012.

10. Kim SH, Bommareddy A and Singh SV: Garlic constituent diallyl trisulfide suppresses $\mathrm{x}$-linked inhibitor of apoptosis protein in prostate cancer cells in culture and in vivo. Cancer Prev Res 4 897-906, 2011.

11. Liu Y, Zhu P, Wang Y, Wei Z, Tao L, Zhu Z, Sheng X, Wang S, Ruan J, Liu Z, et al: Antimetastatic therapies of the polysulfide diallyl trisulfide against triple-negative breast cancer (TNBC) via suppressing MMP2/9 by blocking NF- $\kappa \mathrm{B}$ and ERK/MAPK signaling pathways. PLoS One 10: e0123781, 2015.

12. Shin DY, Cha HJ, Kim GY, Kim WJ and Choi YH: Inhibiting invasion into human bladder carcinoma 5637 cells with diallyl trisulfide by inhibiting matrix metalloproteinase activities and tightening tight junctions. Int J Mol Sci 14: 19911-19922, 2013.

13. Chandra-Kuntal K, Lee J and Singh SV: Critical role for reactive oxygen species in apoptosis induction and cell migration inhibition by diallyl trisulfide, a cancer chemopreventive component of garlic. Breast Cancer Res Treat 138: 69-79, 2013.

14. Choi YH and Park HS: Apoptosis induction of U937 human leukemia cells by diallyl trisulfide induces through generation of reactive oxygen species. J Biomed Sci 19: 50, 2012.

15. Kim YA, Xiao D, Xiao H, Powolny AA, Lew KL, Reilly ML Zeng Y, Wang Z and Singh SV: Mitochondria-mediated apoptosis by diallyl trisulfide in human prostate cancer cells is associated with generation of reactive oxygen species and regulated by Bax/Bak. Mol Cancer Ther 6: 1599-1609, 2007.

16. Shin DY, Kim GY, Hwang HJ, Kim WJ and Choi YH: Diallyl trisulfide-induced apoptosis of bladder cancer cells is caspasedependent and regulated by PI3K/Akt and JNK pathways. Environ Toxicol Pharmacol 37: 74-83, 2014.

17. Wang YB, Qin J, Zheng XY, Bai Y, Yang K and Xie LP: Diallyl trisulfide induces Bcl-2 and caspase-3-dependent apoptosis via downregulation of Akt phosphorylation in human T24 bladder cancer cells. Phytomedicine 17: 363-368, 2010.

18. Zhou W, Hao M, Du X, Chen K, Wang G and Yang J: Advances in targeted therapy for osteosarcoma. Discov Med 17: 301-307, 2014.

19. Zhang YK, Zhang XH, Li JM, Sun S, Yang Q and Diao DM A proteomic study on a human osteosarcoma cell line Saos-2 treated with diallyl trisulfide. Anticancer Drugs 20: 702-712, 2009.

20. Li J, Liu W, Zhao K, Zhang Y, Li X, Yang Q, Li Z and Li J: Diallyl trisulfide reverses drug resistance and lowers the ratio of $\mathrm{CD}_{133^{+}}$ cells in conjunction with methotrexate in a human osteosarcoma drug-resistant cell subline. Mol Med Rep 2: 245-252, 2009.

21. Salvioli S, Ardizzoni A, Franceschi C and Cossarizza A: JC-1, but not $\mathrm{DiOC}_{6}(3)$ or rhodamine 123, is a reliable fluorescent probe to assess $\Delta \Psi$ changes in intact cells: Implications for studies on mitochondrial functionality during apoptosis. FEBS Lett 411: 77-82, 1997.

22. Zhou C,Mao XP, Guo Q and Zeng FQ: Diallyl trisulphide-induced apoptosis in human melanoma cells involves downregulation of Bcl-2 and Bcl-xL expression and activation of caspases. Clin Exp Dermatol 34: e537-e543, 2009.

23. Xu L, Yu J, Zhai D, Zhang D, Shen W, Bai L, Cai Z and Yu C: Role of JNK activation and mitochondrial Bax translocation in allicin-induced apoptosis in human ovarian cancer SKOV3 cells. Evid Based Complement Alternat Med 2014: 378684, 2014.
24. Antico Arciuch VG, Elguero ME, Poderoso JJ and Carreras MC Mitochondrial regulation of cell cycle and proliferation. Antioxid Redox Signal 16: 1150-1180, 2012.

25. Li Y, Zhang J, Zhang L, Si M, Yin H and Li J: Diallyl trisulfide inhibits proliferation, invasion and angiogenesis of osteosarcoma cells by switching on suppressor microRNAs and inactivating of Notch-1 signaling. Carcinogenesis 34: 1601-1610, 2013.

26. Ma HB, Huang S, Yin XR, Zhang Y and Di ZL: Apoptotic pathway induced by diallyl trisulfide in pancreatic cancer cells. World J Gastroenterol 20: 193-203, 2014.

27. Wang HC, Yang JH, Hsieh SC and Sheen LY: Allyl sulfides inhibit cell growth of skin cancer cells through induction of DNA damage mediated G2/M arrest and apoptosis. J Agric Food Chem 58: 7096-7103, 2010.

28. Xiao D, Zeng Y, Hahm ER, Kim YA, Ramalingam S and Singh SV: Diallyl trisulfide selectively causes Bax- and Bak-mediated apoptosis in human lung cancer cells. Environ Mol Mutagen 50: 201-212, 2009.

29. Kyomoto R, Kumazawa H, Toda Y, Sakaida N, Okamura A, Iwanaga M, Shintaku M, Yamashita T, Hiai $\mathrm{H}$ and Fukumoto $\mathrm{M}$ : Cyclin-D1-gene amplification is a more potent prognostic factor than its protein over-expression in human head-and-neck squamous-cell carcinoma. Int J Cancer 74: 576-581, 1997.

30. Karimian H, Moghadamtousi SZ, Fadaeinasab M, GolbabapourS, Razavi M, Hajrezaie M, Arya A, Abdulla MA, Mohan S, Ali HM, et al: Ferulago angulata activates intrinsic pathway of apoptosis in MCF-7 cells associated with $\mathrm{G}_{1}$ cell cycle arrest via involvement of p21/p27. Drug Des Devel Ther 8: 1481-1497, 2014.

31. Park HS, Han MH, Kim GY, Moon SK, Kim WJ, Hwang HJ, Park KY and Choi YH: Sulforaphane induces reactive oxygen species-mediated mitotic arrest and subsequent apoptosis in human bladder cancer 5637 cells. Food Chem Toxicol 64: 157-165, 2014.

32. Jeong JB, Choi J, Baek SJ and Lee SH: Reactive oxygen species mediate tolfenamic acid-induced apoptosis in human colorectal cancer cells. Arch Biochem Biophys 537: 168-175, 2013.

33. Rasul A, Di J, Millimouno FM, Malhi M, Tsuji I, Ali M, Li J and Li X: Reactive oxygen species mediate isoalantolactoneinduced apoptosis in human prostate cancer cells. Molecules 18: 9382-9396, 2013.

34. Na HK, Kim EH, Choi MA, Park JM, Kim DH and Surh YJ: Diallyl trisulfide induces apoptosis in human breast cancer cells through ROS-mediated activation of JNK and AP-1. Biochem Pharmacol 84: 1241-1250, 2012.

35. Lee BC, Park BH, Kim SY and Lee YJ: Role of Bim in diallyl trisulfide-induced cytotoxicity in human cancer cells. J Cell Biochem 112: 118-127, 2011.

36. Zhang J, Yu XH, Yan YG, Wang C and Wang WJ: PI3K/Akt signaling in osteosarcoma. Clin Chim Acta 444: 182-192, 2015.

37. Hahne JC, Honig A, Meyer SR, Gambaryan S, Walter U, Wischhusen J, Häussler SF, Segerer SE, Fujita N, Dietl J, et al: Downregulation of AKT reverses platinum resistance of human ovarian cancers in vitro. Oncol Rep 28: 2023-2028, 2012.

38. Peng SF, Lee CY, Hour MJ, Tsai SC, Kuo DH, Chen FA, Shieh PC and Yang JS: Curcumin-loaded nanoparticles enhance apoptotic cell death of U2OS human osteosarcoma cells through the Akt-Bad signaling pathway. Int J Oncol 44: 238-246, 2014. 